\title{
“LA ATENUACIÓN DEL PRINCIPIO DE EJECUTIVIDAD DEL ACTO ADMINISTRATIVO EN LA LEY FEDERAL DE PROCEDIMIENTO ADMINISTRATIVO.
}

\author{
Luis Darío Ángeles González ${ }^{1}$
}

Sumario: I. Introducción. II. La ejecutividad del acto administrativo. III. La morigeración del principio de la ejecutividad del acto administrativo. IV. Conclusiones.

\section{Resumen}

Este texto presenta una postura interpretativa de los efectos suspensivos (lo que modifica la concepción clásica de la ejecutividad inmediata del acto administrativo) del recurso de revisión previsto por la Ley Federal de Procedimiento Administrativo. Se analiza el concepto de la ejecutividad del acto administrativo a la luz de su regulación, de la doctrina y de la interpretación jurisprudencial en la materia, así como las consecuencias, en favor del administrado como lo son el traslado de la carga argumentativa a la autoridad administrativa y la posibilidad de obtener medidas cautelares en sede judicial para impedir la ejecución del acto administrativo.

Palabras clave: acto administrativo, efectos suspensivos, medidas cautelares

\begin{abstract}
This paper presents an interpretative posture of the suspensive effect (which modify the classical conception of the immediate enforceability of the administrative act) of judicial review governed by the Federal law on administrative procedure. It analizes the concept of the enforceability of the administrative act in the light of its regulation, the doctrine and jurisprudential interpretation on the subject, as well as the consequences, in favour of the managed such as the transfer of the argumentative load to the administrative authority and the possibility of obtaining precautionary measures to prevent the execution of the administrative act.
\end{abstract}

Key words: administrative act, suspensive effect and precautionary measures

1 El autor es Licenciado en Derecho por la Facultad Libre de Derecho de Monterrey. Maestría en Derecho Administrativo por la Universidad Austral de Buenos Aires, Argentina. Socio del despacho "Ángeles Abogados, Firma Legal", S.C. 


\section{Introducción}

El derecho mexicano se encuentra todavía fuertemente influenciado por el positivismo legalista desarrollado en la primera mitad del siglo XX. La consecuencia natural del fuerte arraigo de esta corriente en nuestra concepción del derecho es el sostenimiento de muchos conceptos jurídicos (y sus efectos) por el sólo hecho de que así se han entendido siempre o por ser doctrinas consolidadas. Es el mantenimiento de los dogmas por el hecho de ser, precisamente, dogmas.

Este mantenimiento de las formas por el mero hecho de ser las formas nos ha llevado a caer claramente en lo que podría denominarse la paradoja de la justicia mexicana, consistente en que por el fervor en defender la pureza de los conceptos se cae en la injusticiabilidad de las causas. ${ }^{2}$

Pues bien, el presente texto pretende hacer referencia a uno de esos dogmas: el de la improcedencia de la suspensión, como regla general, del acto administrativo en virtud de la ejecutividad inherente a éste.

La ejecutividad, como tendremos oportunidad de ampliar en otro apartado del presente texto, se ha considerado una de las características inherentes al acto administrativo, la cual implica que en principio éste surte sus efectos independientemente de los recursos legales que se opongan al mismo o, lo que es, que la interposición de medios de defensa en contra de un acto administrativo no implican la suspensión del mismo.

\footnotetext{
${ }^{2}$ No es una queja aislada. El ahora Ministro de la Suprema Corte de Justicia de la Nación Arturo Zaldívar Lelo de Larrea escribió hace algunos años, al referirse a la suspensión en el juicio de amparo y la tradicional postura de la jurisprudencia y la doctrina mexicanas, que "En beneficio de la pureza semántica se sacrificó un mejor funcionamiento de la institución.", aludiendo a la corriente que señala que a la suspensión no se le podía dotar de ciertos efectos restitutorios pues esto sería desnaturalizar la institución. En: Zaldívar Lelo de Larrea, Arturo. Hacia una nueva ley de amparo. $3^{\text {a }}$ ed., México, Porrúa, 2010. Pág. 83
} 
En la actualidad es claro que dicha postura conlleva en un gran número de casos a la injusticiabilidad del acto que causa una afectación al particular, puesto que una gran mayoría de los despliegues que lleva a cabo la administración pública surten plenamente sus efectos a la brevedad de su emisión; por otra parte, las cargas de trabajo de los órganos encargados de la impartición de justicia en la materia, provoca que los medios de defensa impliquen amplios plazos para su resolución definitiva, en desmedro de los Derechos Humanos de los gobernados sometidos a las relaciones frente a las autoridades administrativas.

En suma, frente al despliegue normal de la actividad de la administración pública, aunado al efecto ejecutivo de sus actos y ante la carencia de un sistema efectivo de medidas cautelares para la tutela preventiva de los derechos e intereses de los gobernados, se puede caer fácilmente en el abuso de las prerrogativas de la administración en perjuicio definitivo de los gobernados.

Por esta razón el presente texto propone una interpretación distinta de la ejecutividad en la regulación del acto administrativo a nivel federal, es decir en la Ley Federal de Procedimiento Administrativo, acorde a la regulación legal de dicha característica y la tendencia en que actualmente nos encontramos inscritos de privilegiar la tutela judicial efectiva como un medio para la salvaguarda definitiva de los derechos humanos de los gobernados. ${ }^{3}$

Para desarrollar el presente texto procederemos a analizar la ejecutividad como una consecuencia de la presunción de legalidad del acto administrativo, presentando la regulación legal así como la interpretación jurisprudencial del tema, así como los distintos comentarios que la doctrina ha emitido respecto al tema, para después explicar la regulación normativa de la suspensión de los efectos del acto administrativo en el ordenamiento mexicano, y el razonamiento del por qué

\footnotetext{
${ }^{3}$ Cabe señalar que las distintas oposiciones que se podrían señalar a la propuesta que se hace en el presente texto, en nuestra opinión se ven necesariamente superadas ante el cambio de paradigma que sufrió el sistema mexicano mediante la denominada reforma en materia de Derechos Humanos de 10 de junio de 2011, la cual obliga necesariamente a reformular una gran cantidad de conceptos del derecho mexicano.
} 
consideramos que este contiene una atenuación del citado principio. Finalmente expondremos algunas de las consecuencias que conlleva la interpretación que se propone.

\section{II.La ejecutividad del acto administrativo}

Dado que el presente texto se centra en la ejecutividad, cabe partir de la base de que el acto administrativo cuenta entre sus características con la de ser ejecutorio o que apareja ejecutividad.

Este principio del acto consiste, esencialmente, en que una vez emitido constriñe a su cumplimiento, independientemente de los posibles vicios que presente el acto o, lo que es, no requiere en principio de actuación posterior para la plena realización de sus efectos. ${ }^{4}$

La Ley Federal de Procedimiento Administrativo de México recoge en su regulación este principio al indicar:

"Artículo 8.- El acto administrativo será válido hasta en tanto su invalidez no haya sido declarada por autoridad administrativa o jurisdiccional, según sea el caso.

Artículo 9.- El acto administrativo válido será eficaz y exigible a partir de que surta efectos la notificación legalmente efectuada. (...)"

Bien, como se desprende de los artículos anteriormente citados, la ejecutoriedad ${ }^{5}$ del acto administrativo es una característica legalmente reconocida por el ordenamiento.

Veamos cómo ha recogido la jurisprudencia dicha característica.

4 Tron Petit, Jean Claude y Ortiz Reyes, Gabriel. La nulidad de los actos administrativos. $4^{a}$ ed., México, Ed. Porrúa, 2011, pág. 325; COMADIRA, Julio Rodolfo. El acto administrativo. En la Ley Nacional de Procedimientos Administrativos. $1^{a}$ ed., Argentina, Ed. La Ley, 2002. $5^{a}$ reimpresión, 2009, pág. 177. García De Enterría, Eduardo y Fernández, Tomás-Ramón. Curso de Derecho Administrativo I. $13^{\mathrm{a}}$ ed., España, Ed. Civitas, 2006, pág. 583

${ }^{5}$ En este momento no hacemos distinción entre el uso del vocablo "ejecutoriedad" y "ejecutividad". 
La Primera Sala de la Suprema Corte de Justicia de la Nación ha indicado que:

EJECUTIVIDAD DEL ACTO ADMINISTRATIVO. EL ARTÍCULO 9o. DE LA LEY FEDERAL DE PROCEDIMIENTO ADMINISTRATIVO QUE LA PREVÉ, NO TRANSGREDE LA GARANTÍA DE EFECTIVA TUTELA JURISDICCIONAL. La presunción de legalidad y validez del acto administrativo establecida en el artículo 80. de la Ley citada es la base que sustenta su ejecutividad, pues lleva inmersa la posibilidad de que la administración pública provea a la realización de sus propias decisiones, siempre y cuando el orden jurídico le haya conferido expresamente tal atribución, característica que se constituye en una potestad imperativa o de mando con que se halla investido todo órgano administrativo público y cuyo apoyo radica, básicamente, en el hecho de que en la acción ejecutiva busca satisfacer las necesidades de interés general de la colectividad, cuya realización no admite demora. Por tanto, el artículo 9o. de la Ley Federal de Procedimiento Administrativo, al disponer que el acto administrativo válido será eficaz y exigible a partir de que surta efectos la notificación legalmente efectuada, sin condicionar su ejecutividad a que el acto haya adquirido firmeza derivada del fenecimiento del plazo para controvertirlo, no transgrede la garantía de efectiva tutela jurisdiccional contenida en el artículo 17 de la Constitución Política de los Estados Unidos Mexicanos, en virtud de que no se priva o restringe al afectado del acceso a la jurisdicción con requisitos innecesarios, excesivos, carentes de razonabilidad o limitativos de los plazos pertinentes para alcanzarla, ya que dichos actos administrativos no son definitivos y, en consecuencia, el particular tiene a su alcance medios de impugnación como el recurso de revisión contenido en la Ley en cita, o el juicio de nulidad regulado por la Ley Federal de Procedimiento Contencioso Administrativo, que inclusive prevén la suspensión del acto administrativo combatido, y cuya determinación de nulidad produce efectos retroactivos, con lo cual se logra que las situaciones jurídicas afectadas vuelvan al estado que guardaban antes de la emisión del acto anulado. PRIMERA SALA Amparo en revisión 389/2007. Festo Pneumatic, S.A. 8 de agosto de 2007. Cinco votos. Ponente: José de Jesús Gudiño Pelayo. Secretario: Mario César Flores Muñoz. ${ }^{6}$

Como se puede observar en el criterio citado, la Primera Sala consideró correctamente que la presunción de legalidad del acto administrativo es el

${ }^{6}$ Época: Novena Época. Registro: 171474. Instancia: PRIMERA SALA. Tipo Tesis: Tesis Aislada. Fuente: Semanario Judicial de la Federación y su Gaceta. Localización: Tomo XXVI, Septiembre de 2007. Materia(s): Constitucional, Administrativa. Tesis: 1a. CCV/2007. Pág. 382. [TA]; 9a. Época; 1a. Sala; S.J.F. y su Gaceta; Tomo XXVI, Septiembre de 2007; Pág. 382. 
sustento de la ejecutividad, característica que permite llevar a cabo los efectos del acto de forma directa sin necesidad de que éste adquiera firmeza por el transcurso del tiempo para impugnarlo o por haber agotado los recursos legales para ello.

En el mismo sentido se ha pronunciado de forma unánime la doctrina al señalar que:

"Las Administraciones públicas no sólo tienen el privilegio de dictar decisiones obligatorias, no sólo tienen la facultad de crear sus derechos mediante decisiones unilaterales, sino que ostentan, además, el privilegio de realizar materialmente la decisión con, sin o contra la voluntad del obligado."7

Partiendo de lo anterior, y de forma coherente con esta característica del acto administrativo, se dispone que la impugnación del mismo no conlleva, por regla general, la suspensión de sus efectos. A esto se le denomina el efecto devolutivo de la impugnación del acto administrativo, acorde a la distinción procesal entre recursos con efecto devolutivo o suspensivo. ${ }^{8}$

Cabe aclarar que la Ley Federal de Procedimiento Administrativo no dispone, a diferencia de otros ordenamientos, ${ }^{9}$ los efectos de impugnación devolutiva del recurso administrativo. No obstante lo anterior la postura de la Segunda Sala de la Suprema Corte de Justicia de la Nación de México ha sido en

${ }^{7}$ González Pérez, Jesús. Manual de Procedimiento Administrativo. $2^{\mathrm{a}}$ ed., España, Ed. Civitas, 2002. Pág. 243. En el mismo sentido: Tron Petit, Jean Claude y Ortiz Reyes, Gabriel. La nulidad de los actos administrativos. $2^{\mathrm{a}}$ ed., México, Ed. Porrúa, 2007. Pág. 71

8 "Aparece así la llamada "autotutela ejecutiva", con sus dos expresiones: "coactiva" - el Derecho autoriza el uso de la violencia legítima para la aplicación del acto, como principio - y "de impugnación devolutiva", - en el sentido de otorgarse efecto no suspensivo a las impugnaciones por su mera condición de tales-." García Pullés, Fernando R. Medidas <<cautelares autónomas>> en el contencioso administrativo. $1^{\text {a }}$ ed., Argentina, Ed. Hammurabi, 2006, pág. 32. Las negritas y el subrayado son nuestros.

9 Puede verse el artículo 111 de la Ley del Régimen Jurídico de las Administraciones Públicas y del Procedimiento Administrativo de España, así como el artículo 12 de la Ley Nacional de Procedimiento Administrativo (Ley 19,549) de Argentina. 
el sentido de interpretar el carácter no suspensivo, por regla general, de los recursos administrativos. ${ }^{10}$

\section{III.- La morigeración del principio de la ejecutividad del acto} administrativo. Bien, como hemos señalado con anterioridad, consideramos que el ordenamiento mexicano contiene un elemento que morigera el principio de ejecutividad, en tanto que autoriza la suspensión del acto reclamado como una regla general vía el silencio afirmativo.

Cabe citar las normas correspondientes, previo a la explicación de lo que venimos señalando, para facilitar la exposición. La Ley Federal de Procedimiento Administrativo expresa lo siguiente:

“Artículo 87.- La interposición del recurso suspenderá la ejecución del acto impugnado, siempre y cuando:

I. Lo solicite expresamente el recurrente;

II. Sea procedente el recurso;

III. No se siga perjuicio al interés social o se contravengan disposiciones de orden público;

IV. No se ocasionen daños o perjuicios a terceros, a menos que se garanticen éstos para el caso de no obtener resolución favorable; y

V. Tratándose de multas, el recurrente garantice el crédito fiscal en cualesquiera de las formas prevista en el Código Fiscal de la Federación.

La autoridad deberá acordar, en su caso, la suspensión o la denegación de la suspensión dentro de los cinco días siguientes a su interposición, en cuyo defecto se entenderá otorgada la suspensión."

${ }^{10}$ Así fue resuelto en el Amparo en revisión 1091/2007 del índice de la Segunda Sala de la Suprema Corte de Justicia de la Nación. En este fallo se argumenta, esencialmente, que: a.- Las decisiones de la autoridad administrativa son inmediatamente eficaces y crean en una obligación de cumplimiento inmediato, con independencia de su validez intrínseca; b.- Esto se justifica en que una característica del acto administrativo es que goza de la presunción de legalidad y validez iuris tantum que opera hasta en tanto no se declare la invalidez del mismo; c.- El acto administrativo se presume legítimo en la medida en que emana de una autoridad que también lo es; d.- La presunción de legalidad y validez está contenida en el artículo $8^{\circ}$ de la Ley Federal de Procedimiento Administrativo; e.La presunción de legalidad y validez del acto administrativo es la base de sustento de su ejecutoriedad. Previsión que además es indispensable para lograr la efectiva actividad de la autoridad administrativa. 
Como se desprende de la norma citada, el ordenamiento autoriza la suspensión del acto administrativo en todos los casos en que se configura el silencio administrativo, al cual le dan efecto estimatorio. ${ }^{11}$

Además el silencio se configura por el mero transcurso del tiempo sumado a la omisión de la administración de pronunciarse al respecto, es decir, sin que se requiera actuación adicional por parte del administrado (como la solicitud de una certificación, ${ }^{12}$ o la constitución en mora), o de la administración.

Pues bien, en este punto y de acuerdo con nuestra postura, consideramos que la regulación anterior de la suspensión representa una verdadera atenuación del principio de ejecutividad del acto administrativo con, cuando menos, tres consecuencias, a saber:

1.- En primer lugar, da cobertura legal al silencio administrativo, constituyendo un derecho que se integra a la esfera jurídica del administrado a favor del cual se configuró la omisión de la administración. La integración a la esfera jurídica de dicho acto favorable conlleva obviamente las garantías propias de este tipo de actos, esencialmente, la irrevocabilidad en sede administrativa del mismo.

2.- En segundo lugar, y esto en el marco más amplio de la regulación de la figura suspensiva, el régimen traslada la carga argumentativa de la necesidad de

${ }^{11}$ En el ámbito Español existe una disposición muy similar respecto a la cual se ha dicho que constituye: "una innovación tan importante como plausible - la aplicación al caso del silencio positivo, de forma que,... el acto se entenderá automáticamente suspendido sin más requisitos, por ministerio de la Ley.", García de Enterría, Eduardo y Fernández, Tomás-Ramón, Ob. Cit., pág. 593. Cabe señalar que algunos Tribunales han considerado que al plazo de 5 días se debe sumar el de los 10 días que la autoridad administrativa tiene para notificar una resolución al particular, sin embargo no debe de perderse de vista que los actos administrativos favorables cobran plena eficacia a partir de su conocimiento por parte del interesado (art. $9^{\circ}$, segundo párrafo de la Ley Federal de Procedimiento Administrativo), por lo que en nuestra opinión el silencio afirmativo se configura a partir del día 6 , sin que se requiera un plazo mayor para su configuración.

12 González Pérez, Jesús. Manual de Procedimiento Administrativo. $2^{\mathrm{a}}$ ed., España, Ed. Civitas, 2002, pág. 343. 
ejecución del acto administrativo a la propia autoridad, quien deberá justificar en el caso de forma razonada el por qué es necesario llevar a cabo la ejecución del acto administrativo o, expresado en forma negativa, por qué en el caso no se justifica el otorgamiento de la suspensión; esto de forma independiente al plazo en que se pronuncie sobre la medida cautelar. ${ }^{13}$

3.- Por último, y como consecuencia de los dos anteriores, el régimen autorizaría a acudir a las instancias judiciales correspondientes ya que se desconozca la eficacia del silencio estimatorio, ya que no se cumpla en la especie con la carga argumentativa a cargo de la autoridad para sostener la ejecutividad inmediata del acto. En el primer caso por desconocer un derecho integrado a la esfera jurídica del administrado; en el segundo, al incumplirse los requisitos propios del acto administrativo.

De lo anterior, nuestra conclusión es que en el sistema de la Ley Federal de Procedimiento Administrativo el principio de la ejecutividad del acto administrativo se encuentra atenuado.

Esto se refuerza, además, al hacer especial referencia al procedimiento legislativo, ${ }^{14}$ del cual se desprende la clara intención que inspiró a la Ley, en el sentido de una amplia procedencia de la suspensión del acto administrativo.

Así, de la iniciativa presentada, se desprende que en el proyecto original, la propuesta del artículo 87 establecía: "Por la sola interposición del recurso se suspenderá la ejecución del acto impugnado, salvo aquellos casos que se siga perjuicio al interés social o se contravengan disposiciones de orden público.".

\footnotetext{
${ }^{13}$ No debe perderse de vista que esto no sería sino traspasar la opinión doctrinal de que, para obtener la suspensión del acto administrativo, o denegar la misma, se debe atender al interés público concreto y particular que en el caso se tiene para ejecutar el acto, y no, en cambio a un interés público abstracto y general. En este sentido: González Pérez, Jesús. Procedimiento Administrativo Federal. $3^{a}$ ed., México, Ed. Porrúa, 2000, pág. 60

14 Las citas utilizadas a continuación fueron consultadas en la página: http://www.scjn.gob.mx/normativa/Paginas/Legislacion.aspx consultada el día 21 de noviembre de 2012.
} 
Como se puede observar, la estructura de la norma era clara: la sola interposición del recurso suspenderá la ejecución.

Posteriormente en el dictamen de la Cámara de Senadores, actuando como cámara de origen en el procedimiento legislativo se indicó que:

"20. Un aspecto de vital importancia, para salvaguardar los derechos de los administrados, es el relativo a la suspensión del acto impugnado cuando se interpone el recurso previsto en la ley, por lo que se ha considerado conveniente que el artículo 87 contemple esta posibilidad, siempre que se satisfagan los requisitos que se disponen en el mismo."

Siguiendo esta consideración, el dictamen sometido a votación modificó la norma citada para proponer la redacción que guarda el artículo vigente. No obstante lo anterior, al ser dictaminada la Ley en la Cámara de Diputados, actuando como cámara revisora, se expresó que la iniciativa consideraba, originalmente que: "La sola interposición del recurso suspende la ejecución del acto impugnado, salvo aquellos casos que se siga perjuicio al interés social o se contravengan disposiciones de orden público.", y que las modificaciones llevadas a cabo y que quedaron plasmadas en la vigente ley en el artículo indicado "fueron para dar mayor precisión a los casos en que la interposición del recurso de revisión suspende la ejecución del acto impugnado.".

Así, y siguiendo la evolución legislativa, puede entenderse que el artículo se estableció con la clara intención de autorizar la suspensión en todos los casos, por regla general, y que la redacción definitiva solamente se llevó a cabo en el sentido de precisar las condiciones en que se actualizaría la suspensión, no, por el contrario, para establecer la regla general del efecto devolutivo de los recursos administrativos como se ha pretendido en los criterios jurisdiccionales que hemos expuesto con anterioridad.

En conclusión, la ejecutividad del acto administrativo se encuentra atenuada en su concepción tradicional. 
Esto, además, consideramos que es acorde a la tendencia que busca en la actualidad revalorar el alcance de los derechos y garantías a favor de los administrados, particularmente la tutela judicial efectiva. ${ }^{15}$

Siguiendo esta línea de razonamiento, se encontraría igualmente presente la tercera consecuencia que indicamos en los otros ordenamientos, en el sentido de que la falta de expresión de los motivos que justifican la necesidad concreta de ejecutar el acto administrativo, autoriza acudir a la instancia judicial solicitando medidas cautelares en contra de la resolución, partiendo de la base del incumplimiento en el deber argumentativo a cargo de la administración de justificar dicho extremo.

\section{Conclusiones.}

De lo expuesto en este breve texto podemos establecer las siguientes conclusiones:

1.- El ordenamiento Mexicano, reconoce el principio de ejecutividad del acto administrativo, y la jurisprudencia ha derivado de él la regla general de que la interposición de recursos administrativos no suspende su ejecución.

2.- No obstante lo anterior, el propio ordenamiento cuenta con una regulación tal de la suspensión del acto administrativo que permite sostener que existe, realmente, una morigeración de la ejecutividad, a través de una amplia procedencia de la suspensión del acto en sede administrativa recursiva, además del establecimiento del silencio estimatorio a favor de la pretensión de suspensión

15 Si bien el concepto de "tutela judicial efectiva" se utiliza a partir de la Constitución Española de 1978 y de ahí se ha proyectado a otras latitudes incluyendo México, nos referimos a la tendencia que se llamaría, en la voz de García de Enterría, "La batalla por las medidas cautelares", en el sentido del largo proceso global por lograr medidas aptas para la tutela provisional de situaciones jurídicas frente a la carga laboral de los órganos jurisdiccionales, con la pretensión final de garantizar definitivamente la tutela del administrado frente a los poderes de la administración. 
para el caso de que la autoridad administrativa sea omisa en pronunciarse sobre la misma.

3.- Considerar la suspensión como la regla general de la interposición del recurso administrativo acarrea importantes consecuencias, entre las que se encuentra, primordialmente, la procedencia de medidas para salvaguardar la situación jurídica generada a partir del silencio administrativo estimatorio. ${ }^{16}$

4.- Por último, sostener la anterior interpretación y sus consecuencias sería acorde a la tutela judicial efectiva, en tanto considera a las medidas cautelares, entre ellas a la suspensión, como medios para garantizar el acceso a la justicia, en beneficio último de los gobernados que es lo que finalmente reclama el reconocimiento de los Derechos Humanos. ${ }^{17}$

Bibliografía citada:

${ }^{16}$ En el caso consideramos particularmente la procedencia del juicio de amparo indirecto en que se alegue la violación al derecho de audiencia previa, en caso de que la autoridad administrativa desconozca la configuración del silencio administrativo o, con posterioridad a la configuración del silencio, emita un acto en que "niegue" la suspensión. Así mismo, cuando no se cumple con la carga argumentativa a cargo de la autoridad, de justificar el interés público particular y concreto que se actualiza en el caso y que justifica la negativa de la suspensión, el órgano jurisdiccional podría emitir medidas cautelares en contra del acto.

17 Es claro que no obstante la denominación hace referencia en principio a los procesos judiciales, bajo el concepto genérico de "tutela judicial efectiva" se incluye, una serie de garantías que se desarrollan en distintos aspectos de la protección jurisdiccional de las personas y que se extienden a todos los tipos de procesos judiciales y administrativos, de ahí que se justifique su utilización al referirnos al recurso administrativo. En este sentido cabe recordar que en relación a la interpretación de este derecho, la Corte Interamericana de Derechos Humanos ha establecido claramente que las garantías judiciales se extienden a cualquier tipo de procedimiento, inclusive en las actuaciones ante las autoridades administrativas. Así ha expresado que: "en cualquier materia, inclusive en la laboral y la administrativa, la discrecionalidad de la administración tiene límites infranqueables, siendo uno de ellos el respeto de los derechos humanos. Es importante que la actuación de la administración se encuentre regulada, y ésta no puede invocar el orden público para reducir discrecionalmente las garantías de los administrados" - Vid: Caso Baena Ricardo y otros Vs. Panamá. Fondo, Reparaciones y Costas. Sentencia de 2 de febrero de 2001. Serie C No. 72, párr. 126 y Caso Vélez Loor Vs. Panamá, supra nota 147, párr. 141. 
COMADIRA, Julio Rodolfo. El acto administrativo. En la Ley Nacional de Procedimientos Administrativos. $1^{\text {a }}$ ed., Argentina, Ed. La Ley, 2002. $5^{\text {a }}$ reimpresión, 2009.

GARCÍA DE ENTERRÍA, Eduardo y FERNÁNDEZ, Tomás-Ramón. Curso de Derecho Administrativo I. 13ª ed., España, Ed. Civitas, 2006.

GARCÍA PULLÉS, Fernando R. Medidas <<cautelares autónomas>> en el contencioso administrativo. $1^{\text {a }}$ ed., Argentina, Ed. Hammurabi, 2006.

GONZÁLEZ PÉREZ, Jesús. Manual de Procedimiento Administrativo. $2^{\mathrm{a}}$ ed., España, Ed. Civitas, 2002.

GONZÁLEZ PÉREZ, Jesús. Procedimiento Administrativo Federal. $3^{\mathrm{a}}$ ed., México, Ed. Porrúa, 2000.

TRON PETIT, Jean Claude y ORTIZ REYES, Gabriel. La nulidad de los actos administrativos. 4ª ed., México, Ed. Porrúa, 2011.

ZALDÍVAR LELO DE LARREA, Arturo. Hacia una nueva ley de amparo. $3^{a}$ ed., México, Porrúa, 2010. 